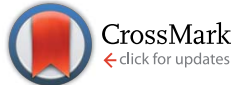

Cite this: Chem. Sci., 2015, 6, 2822

\title{
Highly stable and reusable imprinted artificial antibody used for in situ detection and disinfection of pathogens $\uparrow$
}

\author{
Zhijun Zhang, Yijia Guan, Meng Li, Andong Zhao, Jinsong Ren and Xiaogang Qu*
}

Sandwich ELISA methods have been widely used for biomarker and pathogen detection because of their high specificity and sensitivity. However, the main drawbacks of this assay are the cost, the timeconsuming procedure for the isolation of antibodies and their poor stability. To overcome these restrictions, we herein fabricated artificial antibodies based on imprinting technology and developed a sandwich ELISA for pathogen detection. Both the capture and detection antibodies were obtained via an in situ method, with simplicity, rapidity and low cost. The peroxidase mimics, the $\mathrm{CeO}_{2}$ nanoparticles, as signal generators were integrated with the detection antibody. The fabricated artificial antibodies exhibited not only natural antibody-like binding affinities and selectivities, but also superior stability and

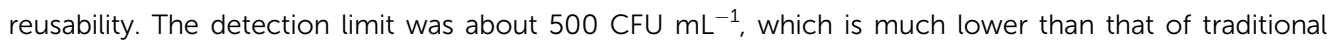
ELISA methods $\left(10^{4}\right.$ to $\left.10^{5} \mathrm{CFU} \mathrm{mL}{ }^{-1}\right)$. Furthermore, the capture antibody can disinfect pathogens in situ.

Received 9th February 2015

Accepted 15th February 2015

DOI: $10.1039 / \mathrm{c} 5 \mathrm{sc00489f}$

www.rsc.org/chemicalscience binding affinity and selectivity. Intriguingly, they can even possess better characteristics than natural antibodies, including easy availability and operability, high stability to harsh chemical and physical conditions, and some even have superior reusability. To date, artificial antibodies against low molecular weight compounds ${ }^{10-12}$ and biological macromolecules ${ }^{13-16}$ based on MIT have been employed for a myriad of applications, such as separation, ${ }^{17}$ biomimetic catalysis, ${ }^{18}$ sensing, ${ }^{19-22}$ sewage treatment, ${ }^{23-25}$ enzyme inhibition ${ }^{26-28}$ and so on. In spite of promising prospects for molecular imprinting, it becomes more challenging as the target size increases, although nanoparticles ${ }^{29}$ and bioentities, such as viruses, ${ }^{30-32}$ microbes ${ }^{33-38}$ and mammalian cells, ${ }^{39,40}$ as templates for artificial antibody fabrication have recently been reported.

Herein, for the first time, we demonstrate a cell imprinted artificial antibodies-based sandwich ELISA for pathogen detection. Both the cAbs and dAbs were synthesized via an imprinting procedure. The cAbs were in situ fabricated on an indium tin oxide (ITO) conductive glass surface through an electrochemically assisted polycondensation method. ${ }^{41,42}$ The dAbs were synthesized using a sol-gel method with cerium dioxide nanoparticles $\left(\mathrm{CeO}_{2} \mathrm{NPs}\right)$ integrated as artificial nanoenzymes. $\mathrm{CeO}_{2}$ NPs have recently been reported to possess excellent peroxidase-like activity toward the substrate $3,3^{\prime}, 5,5^{\prime}$ tetramethylbenzidine (TMB), ${ }^{43-45}$ which can be used to fabricate immunoassays. ${ }^{\mathbf{4 6 7}}$ With the properties of easy availability, and superior stability and reusability, the fabricated artificial antibodies may circumvent the limitations of the natural antibodies and maintain natural antibody-like binding affinities and selectivities. What's more, with their conductivity properties, the cAbs can even disinfect the captured pathogen in situ by using an electrochemical technique. 


\section{Results and discussion}

\section{CAb fabrication}

As illustrated in Fig. 1A, the cAbs were fabricated on an ITO glass surface using Staphylococcus aureus (S. aureus) as a model of the target pathogen, which is one of the five most common causes of nosocomial infections. S. aureus was first immobilized on the aldehyde functionalized ITO glass surface through a Schiff base linkage (Fig. S1A and S1B $\dagger$ ). Subsequently, a silica film was deposited on the electrode surface around the $S$. aureus, via an in situ electrochemically assisted polycondensation method (Fig. S1C $\dagger$ ). ${ }^{\mathbf{4 1} 42}$ Finally, the cAbs were obtained through a calcination treatment. After removal of the template, many regular cavity-cAbs were found to be scattered on the surface of the ITO glass (Fig. 1B and C). Images of the cavities at a higher magnification revealed their circular shape (Fig. 1B and C). The depths of the cavities were measured to be about $160 \mathrm{~nm}$ from the AFM image (Fig. 1C). Evidently, the three-dimensional spheroidal architecture of the template pathogen was imprinted well on the ITO glass surface. The fabrication procedure was also characterized using electrochemical methods (Fig. S2†).

\section{DAbs fabrication}

The enzyme-linked dAbs were obtained through four simple steps: (i) in situ encapsulation of $S$. aureus with a silica shell, (ii) deposition of $\mathrm{CeO}_{2}$ NPs on the silica shell surface, (iii) calcination to remove the template and (iv) ultrasonic treatment to
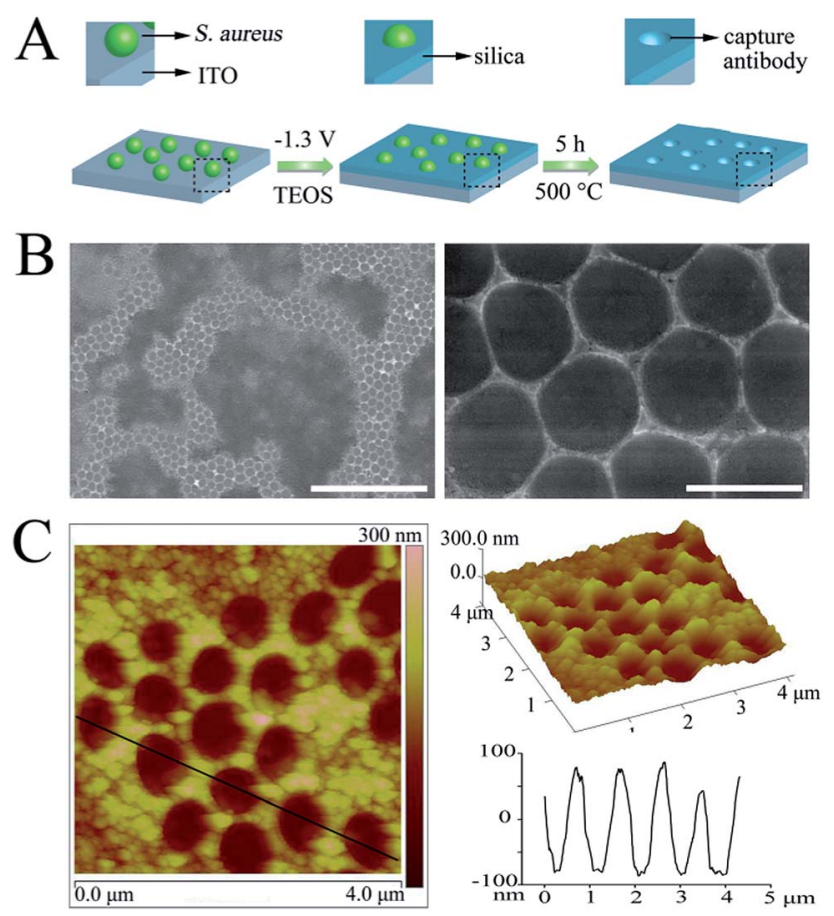

Fig. 1 (A) Schematic diagram outlining the fabrication procedure for the cAbs, (B) SEM micrographs of the cAbs (scale bars $=10 \mu \mathrm{m}$ and $1 \mu \mathrm{m}$, respectively), (C) 2D and 3D AFM images, and the corresponding height profiles of the cAbs. crush the hollow $\mathrm{SiO}_{2} @ \mathrm{CeO}_{2}$ shells (Fig. 2A and $\mathrm{S} 4 \dagger$ ). Fig. 2B shows a typical TEM image of the hollow $\mathrm{SiO}_{2} @ \mathrm{CeO}_{2}$ shells after removal of the template pathogen. The cavities of the hollow spheres were similar in size to $S$. aureus. Meanwhile, a thin $\mathrm{CeO}_{2}$ shell was found to be uniformly deposited on the hollow sphere surface (Fig. 2B and C). After a harsh ultrasonic treatment, the hollow spheres were cracked and cap-like dAbs were obtained (Fig. 2D). The empty cavities of the dAbs were found to maintain the size and shape of the original $S$. aureus. Altogether, these results confirmed that the shape and size of the template pathogen were preserved.

The enzyme that is linked to the $\mathrm{dAb}$ is critical for the assay because it will directly catalyze reaction of the substrate to produce a detectable signal. In the present work, $\mathrm{CeO}_{2} \mathrm{NPs}$ were chosen as artificial nanoenzymes and integrated with the dAb. The oxidation of TMB by $\mathrm{CeO}_{2}$ NPs in the presence of $\mathrm{H}_{2} \mathrm{O}_{2}$ produced a blue color, with two absorbance bands at 370 and $652 \mathrm{~nm}^{43}$ Fig. 2E exhibits the time-dependent absorbance change (at $652 \mathrm{~nm}$ ) for different concentrations of the dAbs. The dAbs demonstrated a high catalytic activity toward the oxidation of TMB. Notably, even $2 \mu \mathrm{g} \mathrm{mL} \mathrm{m}^{-1}$ of the antibodies could produce a detectable signal within $10 \mathrm{~min}$ (Fig. 2E).

\section{Target pathogen recognition tests}

Having successfully fabricated both the cAbs and dAbs, we next investigated the target pathogen recognition capacity of these

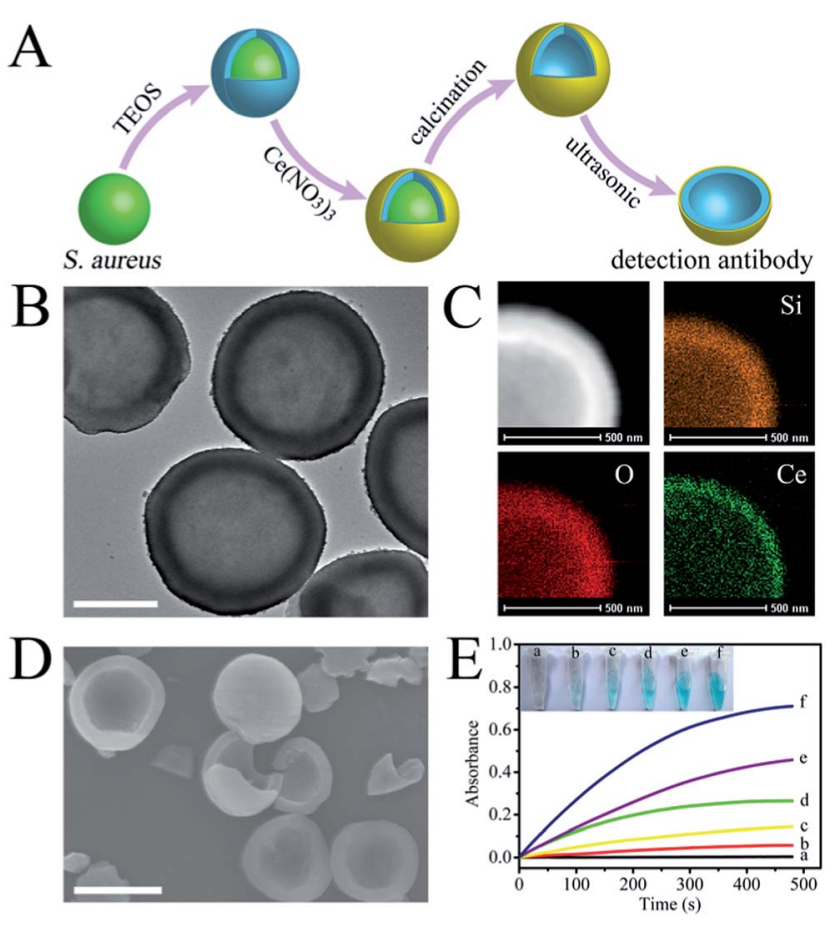

Fig. 2 (A) Schematic representation of the synthesis of the dAbs; (B) TEM image of the hollow $\mathrm{SiO}_{2} \mathrm{CCeO}_{2}$ shells (scale bar $=500 \mathrm{~nm}$ ); (C) dark-field TEM images and the corresponding TEM elemental mappings for the $\mathrm{Si}, \mathrm{O}$ and $\mathrm{Ce}$ signals of the $\mathrm{SiO}_{2} \mathrm{CCeO}_{2}$ shell; (D) SEM image of the dAbs (scale bar $=1 \mu \mathrm{m}$ ); (E) time-dependent absorbance changes at $652 \mathrm{~nm}$ for TMB reaction solutions catalyzed by different concentrations of the dAbs ((a-f): $0,2,5,10,20,50 \mu \mathrm{g} \mathrm{mL}^{-1}$ ). 
antibodies. As shown in Fig. 3A, S. aureus was only found to be present on the imprinted cavities, and none was found in the non-imprinting area, indicating that $S$. aureus could be efficiently captured by the cAbs. Meanwhile, the non-target pathogens Escherichia coli (E. coli) and yeast cells were difficult to find on the plate (Fig. S5 $\dagger$ ). Even Staphylococcus epidermidis (S. epidermidis), which is similar in shape and size to $S$. aureus, was found to be much less captured by the cAbs (Fig. S7†). The recognition capacity of the dAbs was characterized using fluorescence microscopy. For better identification, S. aureus was stained with calcein-AM, to give a green fluorescence. Before photographing, the stained $S$. aureus and dAbs were dispersed in buffer and then moderately shaken for $10 \mathrm{~min}$. As shown in Fig. 3B-D, most of the green fluorescence and crescent-shaped dAbs overlapped at the same spot, revealing that the dAbs were tightly bound to $S$. aureus. The binding specificity of the dAbs was also evaluated. Evidently, the dAbs could specifically bind to $S$. aureus over E. coli, yeast cells and S. epidermidis (Fig. S6 and S7 $\dagger$ ). Taken together, both the fabricated cAbs and dAbs could recognize target pathogens with high specificity. The target pathogen-like size and shape of the imprinted cavities may play an important role for the high recognition and selectivity capability. ${ }^{35,36,40}$ In addition, the imprinting of the surface chemistry of the pathogen at the molecular level would also contribute to the natural antibody-like properties. ${ }^{33,34,40}$

\section{Pathogen detection}

The target pathogen recognition capability of both the cAbs and $\mathrm{dAbs}$, and the high catalytic activity of the dAbs, adequately meet the requirements for construction of a sandwich ELISA. Therefore, a sandwich ELISA based on these artificial antibodies was set up for $S$. aureus detection. A schematic representation of the sandwich ELISA format is presented in Fig. 4A. The target pathogens were first selectively captured by the cAbs-functionalized ITO glass, and subsequently the captured pathogens were recognized by the dAbs. Finally, the blue color was generated through the oxidation of TMB

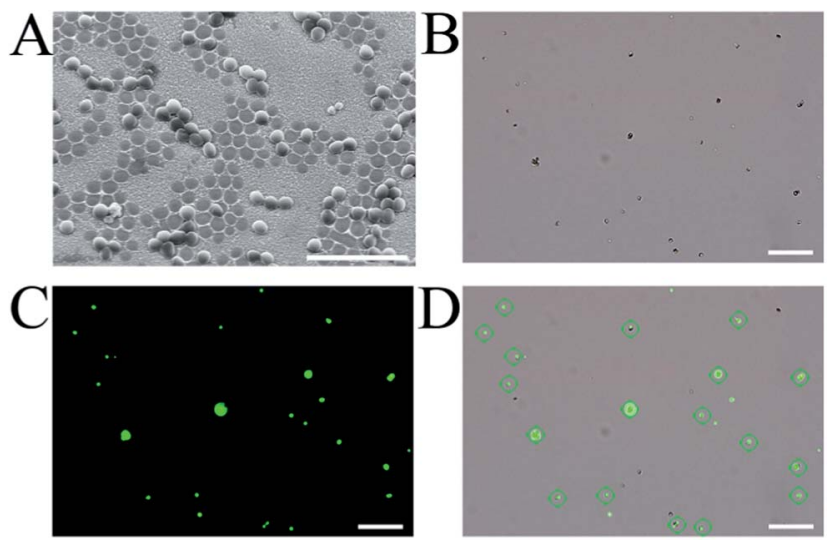

Fig. 3 (A) SEM image of S. aureus captured by the cAbs (scale bar = $5 \mu \mathrm{m})$; (B) bright-field image of the mixture of dAbs and $S$. aureus, (C) fluorescence image revealing the positions of $S$. aureus, (D) an overlay of $(B)$ and $(C)$; the green circles mark the binding of $S$. aureus to the dAbs (scale bar $=10 \mu \mathrm{m}$ ). by the dAbs in the presence of $\mathrm{H}_{2} \mathrm{O}_{2}$. The constructed assay was characterized using SEM imaging. As shown in Fig. 4B, the sandwich structure was clearly observed, showing that $S$. aureus was captured by the cAbs and capped by the dAbs. The detection results are illustrated in Fig. 4C. No visible color was found on the control plate, while a distinguishable blue color appeared in the presence of $S$. aureus at $10^{4} \mathrm{CFU} \mathrm{mL}^{-1}$ (colony-forming units per milliliter). The color deepened gradually as the $S$. aureus concentration increased. UV-vis absorption spectra were used to quantify the results (Fig. 4D). The limit of detection was estimated to be about $500 \mathrm{CFU} \mathrm{mL} \mathrm{m}^{-1}$, which is much lower than that of traditional ELISA methods $\left(10^{4}\right.$ to $\left.10^{5} \mathrm{CFU} \mathrm{mL}{ }^{-1}\right){ }^{48}$ The detection results could also be analyzed using image processing software (Adobe Photoshop) ${ }^{49}$ (Fig. S8 $\dagger$ ). The selectivity of the constructed sandwich ELISA was further investigated using non-target pathogens, E. coli, yeast cells and $S$. epidermidis, as controls. As presented in Fig. 4C, no obvious blue color appeared for the non-target pathogen detections, indicating the high specificity of the fabricated assay. The specific detection capability could be ascribed to the recognition specificity of the artificial antibodies. In addition, the two antibodies recognition strategy also plays an active role.

\section{Reusability tests}

The reusability of natural antibodies is severely hampered by their poor stability. Herein, the artificial antibodies synthesized
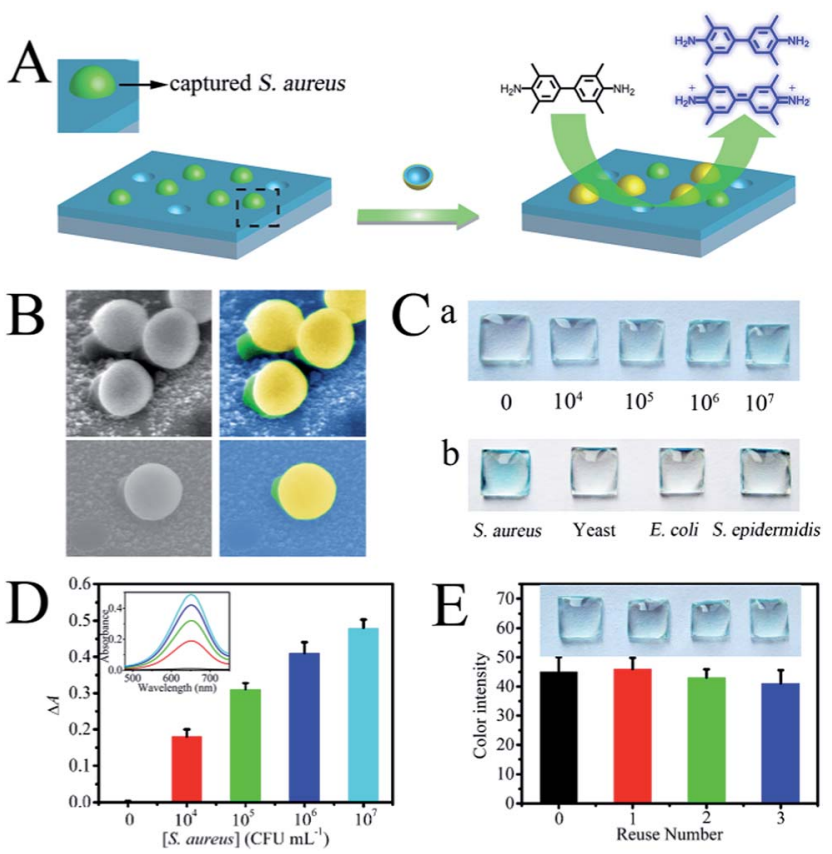

Fig. 4 (A) Schematic illustration of the sandwich ELISA for S. aureus detection, (B) SEM images of the constructed sandwich ELISA (left) and the corresponding false color images (right), (C) images of the colorimetric detection of pathogens using the fabricated sandwich ELISA: (a) different concentrations of $S$. aureus and (b) different pathogens at $10^{7} \mathrm{CFU} \mathrm{mL}^{-1}$, (D) the corresponding absorbance values as determined from the absorption spectra of the test plates in $\mathrm{Ca},(\mathrm{E})$ images of the

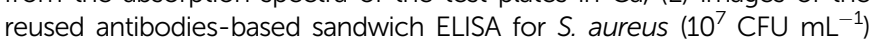
detection (the colour intensity was measured for red in RGB format in Adobe Photoshop). 
went through a high temperature calcination procedure, and they all exhibited high thermal stability. More importantly, both the cAbs and dAbs were found to be reusable through a simple calcination treatment. After calcination, the cAbs were found to maintain their original topography (Fig. S9†) and no obvious attenuation of the catalytic activity of the dAbs was observed (Fig. S10 $\dagger$ ). Even after treatment three times, the recovered sandwich ELISA could give a detection signal as high as $90 \%$ of the initial value (Fig. 4E), indicating their high reusability.

\section{Pathogen electrochemical disinfection}

For healthcare, it is more desirable that the detection and disinfection of pathogens can be realized at the same time. The fabricated cAbs could not only be used to construct a sandwich ELSA for pathogen detection, but could also be available to in situ electrochemically disinfect the captured pathogens. The fluorescent probes calcein-AM and propidium iodide (PI) were used to stain the living cells (green) and dead cells (red), respectively. As shown in Fig. 5A and B, after electrochemical treatment almost all of the $S$. aureus could be stained by PI, indicating that the $S$. aureus was disinfected. The electrochemical oxidation of intracellular coenzyme A (CoA), which is irreversibly converted to a CoA dimer by disulfide bond formation, and disruption of cell membranes have been generally considered to be responsible for disinfection activities. ${ }^{50,51}$ The cell membrane disruption effect was further demonstrated through SEM imaging. As seen in Fig. 5C, the morphology of the
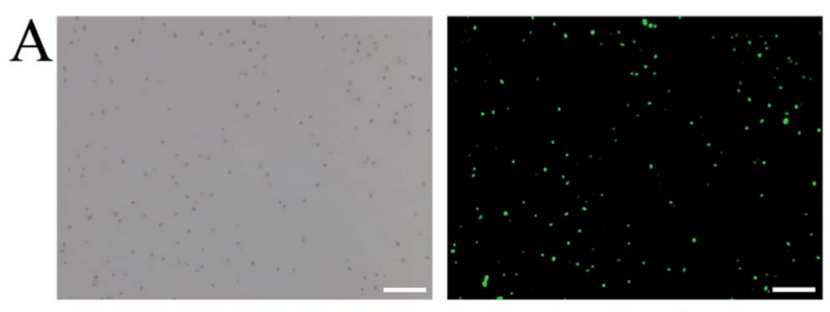

B
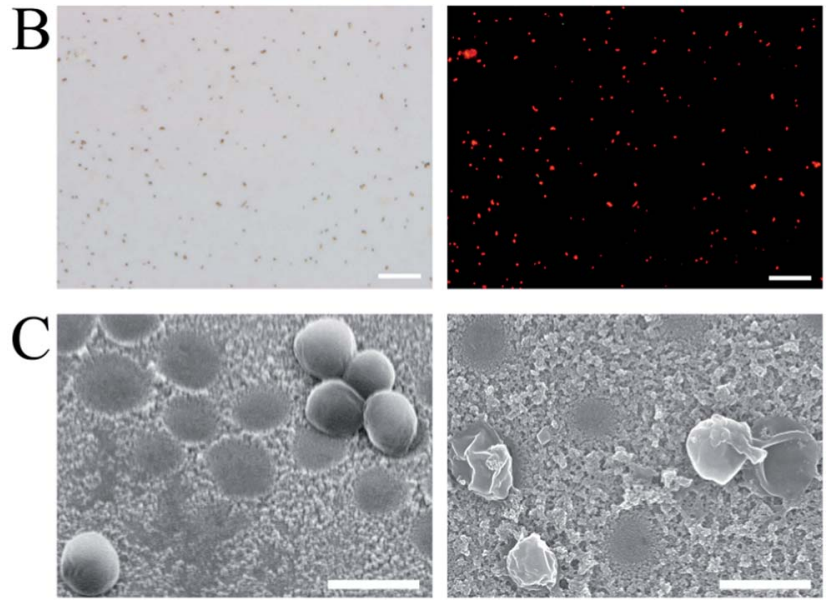

Fig. 5 Optical images of the captured living $S$. aureus (A) and electrochemically disinfected $S$. aureus (B) stained by calcein-AM (green) and $\mathrm{PI}$ (red) (scale bar $=10 \mu \mathrm{m}$ ). (C) SEM images of the captured $S$. aureus cells before (left) and after (right) electrochemical treatment (scale bar $=1 \mu \mathrm{m}$ ).
S. aureus was remarkably disrupted; many cells were found to be greatly shrunken and some had even collapsed.

Taken together, the fabricated artificial antibodies based on imprinting technology can be used for facile construction of a sandwich ELISA for the sensitive detection of pathogens. Compared with recently reported assays for the detection of pathogens (Table $\mathrm{S} 1 \dagger$ ), the most obvious advantage of the present method is that all the construction components are integrative, stable and reusable. In addition, apart from detection, the captured pathogens can even be in situ electrochemically disinfected.

\section{Conclusions}

In summary, for the first time we have fabricated cell imprinted artificial antibodies to set up a sandwich ELISA for pathogen detection. Both the cAbs and dAbs were obtained via in situ methods, with simplicity, rapidity and low cost. The fabricated antibodies could be used without immobilization or an enzyme linkage procedure, which would streamline the process of sandwich ELISA construction. The constructed ELISA could be used for target pathogen detection with high sensitivity and selectivity. What's more, these artificial antibodies possess superior stability and reusability, which may circumvent the limitations of the natural antibodies. Besides, the cAbs can disinfect pathogens in situ by using an electrochemical technique. Thus, the present work may open a new avenue for designing stable and reusable artificial antibodies for immunoassays.

\section{Acknowledgements}

Financial support was provided by the 973 project (2011CB936004, 2012CB720602), and NSFC (21210002, 21431007, 91413111).

\section{References}

1 B. V. Chikkaveeraiah, A. A. Bhirde, N. Y. Morgan, H. S. Eden and X. Chen, ACS Nano, 2012, 6, 6546-6561.

2 R. de la Rica and M. M. Stevens, Nat. Nanotechnol., 2012, 7, 821-824.

3 F. Giavazzi, M. Salina, R. Cerbino, M. Bassi, D. Prosperi, E. Ceccarello, F. Damin, L. Sola, M. Rusnati, M. Chiari, B. Chini, T. Bellini and M. Buscaglia, Proc. Natl. Acad. Sci. U. S. A., 2013, 110, 9350-9355.

4 D. Liu, X. Huang, Z. Wang, A. Jin, X. Sun, L. Zhu, F. Wang, Y. Ma, G. Niu, A. R. Hight Walker and X. Chen, ACS Nano, 2013, 7, 5568-5576.

5 D. Liu, Z. Wang, A. Jin, X. Huang, X. Sun, F. Wang, Q. Yan, S. Ge, N. Xia, G. Niu, G. Liu, A. R. Hight Walker and X. Chen, Angew. Chem., Int. Ed., 2013, 52, 14065-14069.

6 D. M. Rissin, C. W. Kan, T. G. Campbell, S. C. Howes, D. R. Fournier, L. Song, T. Piech, P. P. Patel, L. Chang, A. J. Rivnak, E. P. Ferrell, J. D. Randall, G. K. Provuncher, D. R. Walt and D. C. Duffy, Nat. Biotechnol., 2010, 28, 595599. 
7 L. Chen, S. Xu and J. Li, Chem. Soc. Rev., 2011, 40, 2922-2942. 8 J. E. Lofgreen and G. A. Ozin, Chem. Soc. Rev., 2014, 43, 911933.

9 M. J. Whitcombe, I. Chianella, L. Larcombe, S. A. Piletsky, J. Noble, R. Porter and A. Horgan, Chem. Soc. Rev., 2011, 40, 1547-1571.

10 Y. Fuchs, O. Soppera, A. G. Mayes and K. Haupt, Adv. Mater., 2013, 25, 566-570.

11 X. Shen and L. Ye, Macromolecules, 2011, 44, 5631-5637.

12 D. S. Meador and D. A. Spivak, Org. Lett., 2014, 16, 14021405.

13 S. Beyazit, S. Ambrosini, N. Marchyk, E. Palo, V. Kale, T. Soukka, B. Tse Sum Bui and K. Haupt, Angew. Chem., Int. Ed., 2014, 53, 8919-8923.

14 L. Li, Y. Lu, Z. Bie, H.-Y. Chen and Z. Liu, Angew. Chem., Int. Ed., 2013, 125, 7599-7602.

15 J. Ye, Y. Chen and Z. Liu, Angew. Chem., Int. Ed., 2014, 53, 10386-10389.

16 D. Cai, L. Ren, H. Zhao, C. Xu, L. Zhang, Y. Yu, H. Wang, Y. Lan, M. F. Roberts, J. H. Chuang, M. J. Naughton, Z. Ren and T. C. Chiles, Nat. Nanotechnol., 2010, 5, 597-601.

17 J. L. Urraca, C. S. A. Aureliano, E. Schillinger, H. Esselmann, J. Wiltfang and B. Sellergren, J. Am. Chem. Soc., 2011, 133, 9220-9223.

18 G. Wulff and J. Liu, Acc. Chem. Res., 2011, 45, 239-247.

19 S. Wang, J. Ye, Z. Bie and Z. Liu, Chem. Sci., 2014, 5, 11351140.

20 W. Bai, N. A. Gariano and D. A. Spivak, J. Am. Chem. Soc., 2013, 135, 6977-6984.

21 R. V. Shutov, A. Guerreiro, E. Moczko, I. P. de VargasSansalvador, I. Chianella, M. J. Whitcombe and S. A. Piletsky, Small, 2014, 10, 1086-1089.

22 W. Zhang, W. Liu, P. Li, H. Xiao, H. Wang and B. Tang, Angew. Chem., Int. Ed., 2014, 53, 12489-12493.

23 Y. Ma, G. Pan, Y. Zhang, X. Guo and H. Zhang, Angew. Chem., Int. Ed., 2013, 52, 1511-1514.

24 G. Pan, Y. Zhang, Y. Ma, C. Li and H. Zhang, Angew. Chem., Int. Ed., 2011, 50, 11731-11734.

25 X. Shen, L. Zhu, N. Wang, L. Ye and H. Tang, Chem. Commun., 2012, 48, 788-798.

26 C. Zheng, X. Zhang, W. Liu, B. Liu, H. Yang, Z. Lin and G. Chen, Adv. Mater., 2013, 25, 5922-5927.

27 Y. Yu, L. Ye, K. Haupt and K. Mosbach, Angew. Chem., Int. Ed., 2002, 41, 4459-4463.

28 A. Cutivet, C. Schembri, J. Kovensky and K. Haupt, J. Am. Chem. Soc., 2009, 131, 14699-14702.

29 S. Kraus-Ophir, J. Witt, G. Wittstock and D. Mandler, Angew. Chem., Int. Ed., 2013, 53, 294-298.
30 W. Bai and D. A. Spivak, Angew. Chem., Int. Ed., 2014, 53, 2095-2098.

31 T. Wangchareansak, A. Thitithanyanont, D. Chuakheaw, M. P. Gleeson, P. A. Lieberzeit and C. Sangma, J. Mater. Chem. B, 2013, 1, 2190-2197.

32 A. Cumbo, B. Lorber, P. F. X. Corvini, W. Meier and P. Shahgaldian, Nat. Commun., 2013, 4, 1503.

33 K. Ren, N. Banaei and R. N. Zare, ACS Nano, 2013, 7, 60316036.

34 K. Ren and R. N. Zare, ACS Nano, 2012, 6, 4314-4318.

35 J. Borovička, W. J. Metheringham, L. A. Madden, C. D. Walton, S. D. Stoyanov and V. N. Paunov, J. Am. Chem. Soc., 2013, 135, 5282-5285.

36 J. Borovicka, S. D. Stoyanov and V. N. Paunov, Nanoscale, 2013, 5, 8560-8568.

37 X. Shen, J. Svensson Bonde, T. Kamra, L. Bülow, J. C. Leo, D. Linke and L. Ye, Angew. Chem., Int. Ed., 2014, 53, 10687-10690.

38 Z. Zhang, M. Li, J. Ren and X. Qu, Small, 2014, DOI: 10.1002/ smll.201402400.

39 K. Eersels, B. van Grinsven, A. Ethirajan, S. Timmermans, K. L. Jiménez Monroy, J. F. J. Bogie, S. Punniyakoti, T. Vandenryt, J. J. A. Hendriks, T. J. Cleij, M. J. A. P. Daemen, V. Somers, W. De Ceuninck and P. Wagner, ACS Appl. Mater. Interfaces, 2013, 5, 7258-7267.

40 M. Mahmoudi, S. Bonakdar, M. A. Shokrgozar, H. Aghaverdi, R. Hartmann, A. Pick, G. Witte and W. J. Parak, ACS Nano, 2013, 7, 8379-8384.

41 A. Goux, M. Etienne, E. Aubert, C. Lecomte, J. Ghanbaja and A. Walcarius, Chem. Mater., 2009, 21, 731-741.

42 A. Walcarius, E. Sibottier, M. Etienne and J. Ghanbaja, Nat. Mater., 2007, 6, 602-608.

43 Y. Lin, C. Xu, J. Ren and X. Qu, Angew. Chem., Int. Ed., 2012, 51, 12579-12583.

44 H. Wei and E. Wang, Chem. Soc. Rev., 2013, 42, 6060-6093. 45 C. Xu and X. Qu, NPG Asia Mater., 2014, 6, e90.

46 A. Asati, C. Kaittanis, S. Santra and J. M. Perez, Anal. Chem., 2011, 83, 2547-2553.

47 A. Asati, S. Santra, C. Kaittanis, S. Nath and J. M. Perez, Angew. Chem., Int. Ed., 2009, 48, 2308-2312.

48 P. C. Ray, S. A. Khan, A. K. Singh, D. Senapati and Z. Fan, Chem. Soc. Rev., 2012, 41, 3193-3209.

49 A. W. Martinez, S. T. Phillips and G. M. Whitesides, Proc. Natl. Acad. Sci. U. S. A., 2008, 105, 19606-19611.

$50 \mathrm{~J}$. W. Costerton, B. Ellis, K. Lam, F. Johnson and A. E. Khoury, Antimicrob. Agents Chemother., 1994, 38, 2803-2809.

51 M. Okochi, N. Nakamura and T. Matsunaga, Clean Products and Processes, 1998, 1, 53-59. 